\title{
Ensino das lutas Na EdUCAÇÃo Física Escolar: UM RELATO DE EXPERIÊNCIA FUNDAMENTADO NO ENSINO CENTRADO NO APRENDIZ
}

\author{
TEACHING OF FIGHTS IN SCHOOL PHYSICAL EDUCATION: AN EXPERIENCE \\ REPORT BASED ON LEARNING CENTERED TEACHING
}

DOI: 10.23926/RPD.2526-2149.2020.v5.n2.p823-842.id760

\section{Jaqueline da Silva \\ Mestranda em Educação \\ Física (UFSC) \\ Especialista em Educação \\ Física Escolar \\ (UNIASSELVI) \\ jaquelineds913@gmail.com}

\section{Allana Alexandre \\ Cardoso \\ Doutoranda em Educação \\ Física (UFSC) \\ Mestre em Ciências do \\ Movimento Humano \\ (UDESC) \\ allana.alexandre@gmail.com}

\section{Marcos Paulo Vaz de Campos Pereira}

Doutorando em Ciências do

Movimento Humano

(UDESC)

Mestre em Ciências do

Movimento Humano

(UDESC)

marcosp.pereira46@gmail.co

$\underline{\mathrm{m}}$

\section{Gelcemar Oliveira \\ Farias}

Doutora em Educação Física

(UFSC)

Professora adjunta na

Universidade do Estado de

Santa Catarina (UDESC).

fariasgel@hotmail.com
Resumo: Objetiva-se, neste artigo, descrever uma experiência de ensino das lutas na Educação Física Escolar, envolvendo as possibilidades, as estratégias e os desafios presentes no processo de ensino e aprendizagem desta modalidade. De cunho qualitativodescritivo, este estudo caracteriza-se como um relato de experiência, a qual baseou-se na teoria do ensino centrada no aprendiz, fundamentada nos princípios do construtivismo. A experiência foi realizada no ano de 2018, em uma escola pública municipal da cidade de Blumenau (SC), nas aulas de Educação Física Escolar com a participação de 313 estudantes de $6^{\circ}, 7^{\circ}$ e $8^{\circ}$ anos do ensino fundamental. Os resultados evidenciaram o desenvolvimento de habilidades como criatividade, empatia e reflexividade, bem como ampliação da consciência de si durante o processo e reconhecimento da necessidade de assumir maior responsabilidade pelo próprio aprendizado. Concluiu-se que é possível adotar as lutas como conteúdo, oportunizando aos estudantes papel ativo no processo de ensino e aprendizagem.

Palavras-chave: Luta. Escola. Educação Física.

\begin{abstract}
The aim of this article is to describe an experience of teaching fighting in School Physical Education, involving the possibilities, the strategies and challenges present in the teaching and learning process of this modality. Qualitative and descriptive, this study is characterized as an experience report, which was based on the theory of teaching centered on the apprentice, founded on the principles of constructivism. An experiment carried out in 2018, in a municipal public school in the city of Blumenau (SC), with the participation of 313 students from the 6th, 7th and 8th grades of elementary school. The results showed the development of skills such as creativity, empathy and reflexivity, the expansion of awareness during the process and the recognition of the obligation to assume greater responsibility for learning itself stands out. It was concluded that it is possible to carry out a struggle as content, giving students an active role in the process of teaching and learning development.
\end{abstract}

Keywords: Fights. School. Physical Education. 


\section{INTRODUÇÃO}

A Educação Física, componente curricular obrigatório da educação básica conforme a Lei de Diretrizes e Bases da Educação Nacional (BRASIL, 1996), pauta-se pela diversificação no desenvolvimento de suas unidades temáticas. Os temas a serem abordados encontram-se organizados em propostas curriculares e em documentos oficiais de domínio público, os quais auxiliam os professores na seleção e na organização dos conteúdos da Educação Física Escolar, visando ao significativo aperfeiçoamento dos processos de ensino e de aprendizagem (BRASIL, 2017).

Aos professores de Educação Física cabe implementar os diversos temas de ensino jogos, brincadeiras, esportes, lutas, danças, ginásticas, práticas corporais de aventura oportunizando experiências diversificadas aos estudantes, desenvolvendo sua autonomia e sua criatividade, estimulando-os a participarem em contextos de saúde e lazer (BRASIL, 2017).

Neste conjunto de temas da Educação Física Escolar, encontram-se as lutas. Elas são disputas corporais por meio de técnicas, em que os participantes devem atender objetivos específicos, como imobilizar, desequilibrar e excluir o adversário de um espaço estabelecido (BRASIL, 2017). Gomes (2008) classifica os tipos de lutas conforme a distância, o contato permitido entre dois ou mais participantes em confronto e as técnicas adotadas. Aplica-se a denominação luta quando há um combate, em que se desenvolvem golpes de ataque e defesa, sem violência e deslealdade, difundindo, portanto, princípios educacionais e pedagógicos (BRASIL, 1998; CIRINO; PEREIRA; SCAGLIA, 2013; RUFINO, DARIDO, 2013).

O ensino das lutas em âmbito escolar tem entre seus propósitos ampliar os conhecimentos e o repertório motor dos estudantes, possibilitando que eles usufruam, produzam, reproduzam e transformem as manifestações da cultura corporal de movimento humano (OLIVIER, 2000). Esta modalidade atende, portanto, o papel principal da escola: a formação de cidadãos críticos (RUFINO; DARIDO, 2013). Estudos recentes sobre o tema revelam o reconhecimento do ensino das lutas, quer pela obediência à legislação educacional (BRASIL, 2017), quer pela introdução deste conteúdo nas aulas escolares (PEREIRA et al., 2017).

O ensino das lutas na Educação Física Escolar é pouco oportunizado pelos professores, porque sua prática é limitada a determinadas modalidades; faltam aos professores experiência e segurança para ensiná-las; este conteúdo está ausente da formação inicial; nota-se escassez de literatura específica e há associação das lutas à violência (OLIVIER, 2000; NASCIMENTO; ALMEIDA, 2007; GALATTI; CIRINO; SCAGLIA, 2015; PEREIRA et al., 2017; MIRANDA; 
DOS REIS, 2020). Por conseguinte, restringem-se às possibilidades de experiências através das lutas e prejudica-se a ampliação do repertório motor dos estudantes.

Ressalta-se, contudo, que o conteúdo 'lutas', no contexto escolar, não necessita ser desenvolvido por experts e/ou professores graduados em determinado tipo de luta (GALATTI; CIRINO; SCAGLIA, 2015). É suficiente que os professores tenham a formação e a habilitação requeridas para o exercício da docência em Educação Física. Rufino e Darido (2013) explicam que os professores têm o dever de possibilitar aos estudantes as mais diversas experiências, assegurando-lhes o direito de conhecer diferentes conteúdos e contribuindo para que eles se transformem, aprendam e progridam.

Para o ensino das lutas na Educação Física Escolar, os professores têm adotado diversas metodologias, porém, na maioria das vezes, centraliza-se no professor as tomadas de decisões, como a definição de estratégias, de conteúdos e de procedimentos avaliativos. Isto torna-se uma barreira no processo de ensino e de aprendizagem dos estudantes. Este contexto pode levar à desmotivação e até à desistência dos estudantes da participação nas aulas de Educação Física ao chegarem ao Ensino Médio (DARIDO, 1999).

A fim de se modificar este cenário, procurando um espaço no qual existam equilíbrio de poder e valorização dos conhecimentos prévios dos estudantes, propiciando um contexto com mais significado e sentido para os protagonistas (professor e estudante) (FOSNOT, 2005), sobressai o construtivismo. Esta teoria permite ao estudante desempenhar papel ativo, colocando-o no centro do processo de ensino e de aprendizagem, para que, juntamente com o professor, por meio do diálogo, participe da construção do processo educacional.

Assenta-se, portanto, na base construtivista, o modelo de ensino centrado no aprendiz preconizado por Weimer (2002). Este modelo contempla cinco princípios: função do conteúdo; papel do professor; responsabilidade pela aprendizagem; equilíbrio do poder; finalidades e processos de avaliação. O modelo visa equilibrar a distribuição de responsabilidades e de poderes entre professores e estudantes, promovendo desenvolvimento da autonomia e maior participação dos estudantes nas etapas dos processos de ensino e de aprendizagem. O docente exerce o papel de facilitador da aprendizagem e desenvolve os conteúdos de ensino considerando os conhecimentos prévios, as necessidades e os interesses discentes (WEIMER, 2002).

Poucos estudos relatam práticas das manifestações da cultura corporal de movimento centrada no estudante. Alguns salientam a pouca recorrência de práticas e ensino de lutas, na Educação Física Escolar, e ressaltam o diminuto acesso à temática pelos professores, os quais 
manifestam preocupação e insegurança para abordá-la em aula (ROSÁRIO, DARIDO, 2005; NASCIMENTO; ALMEIDA, 2007; NASCIMENTO, 2008; PEREIRA et al., 2017). Neste contexto, propõe-se o seguinte questionamento como norteador dessa investigação: como implementar as lutas na Educação Física Escolar, possibilitando o papel ativo dos estudantes nesse processo? Logo, este estudo tem por objetivo relatar as possibilidades, as estratégias e os desafios da experiência do ensino das lutas nas aulas de Educação Física, nos anos finais do ensino fundamental, com base na teoria do ensino centrada no aprendiz.

O estudo foi organizado em três grandes seções: cenário da experiência e referencial apresenta o contexto em que ocorreu a experiência de ensino de lutas e o referencial teórico que fundamentou sua implementação; metodologia e desenvolvimento da proposta de ensino das lutas - caracteriza o estudo e demonstra cada etapa de desenvolvimento do conteúdo de lutas durante as aulas, seu processo de avaliação e a realização do festival de lutas; resultados evidencia a conclusão do estudo através dos dados obtidos na experiência de lutas fundamentada na teoria do ensino centrado no aprendiz.

\section{CENÁRIO dA EXPERIÊNCIA E REFERENCIAL}

O estudo foi realizado no segundo semestre do ano de 2018, em uma escola pública municipal da cidade de Blumenau, estado de Santa Catarina, a qual compreende turmas do ensino infantil (pré) ao $9^{\circ}$ ano do ensino fundamental, com funcionamento nos turnos matutino e vespertino. $\mathrm{O}$ contexto da abordagem das lutas abrangeu 313 alunos do ensino fundamental, sendo 141 do $6^{\circ}$ ano (média de idade de 11 anos); 143 do $7^{\circ}$ ano (média de idade de 12 anos); 29 do $8^{\circ}$ ano (média de idade de 13 anos). As aulas de Educação Física Escolar ocorreram com a frequência de três aulas semanais, com duração de 45 minutos cada, sendo realizadas na sala de aula e na quadra de esportes.

Ressalta-se que, anteriormente à implementação da proposta do ensino das lutas, foi oportunizado aos estudantes, no primeiro semestre de 2018, pela mesma professora, a experiência com diferentes estilos de dança, configurando-se em um grande desafio, porque propunha romper com a cultura tradicional da Educação Física, neste caso, as temáticas esportivas.

Para o ensino das lutas foi desenvolvido um planejamento baseado na teoria do ensino centrada no aprendiz (WEIMER, 2002). Em relação aos conteúdos, buscou-se valorizar os conhecimentos prévios dos estudantes sobre as lutas, fomentando um processo significativo e oportunizando o compartilhamento de ideias, sugestões e experiências (FOSNOT, 2005). 
Quanto às estratégias, visou-se o compartilhamento de responsabilidade entre estudantes e professores. Nos processos avaliativos, objetivou-se contemplar estratégias teóricas e práticas de caráter formativo (WEIMER, 2002,2013).

Foi assim construído e promovido um processo de ensino e de aprendizagem caracterizado pelo equilíbrio dinâmico do poder, com decisões tomadas conjuntamente pela professora e pelos estudantes, visando ao papel ativo dos alunos no percurso de seu desenvolvimento (WEIMER, 2002). Os registros no diário de campo da professora constituíram um excelente documento de organização dos dados e sistematização das falas dos estudantes recolhidas a cada aula.

\section{METODOLOGIA E DESENVOLVIMENTO DA PROPOSTA DE ENSINO DAS LUTAS}

Este estudo caracteriza-se como qualitativo, de caráter descritivo (DENZIN; LINCOLN, 2006), e configura-se como um de relato de experiência por apresentar as sequências pedagógicas elaboradas e executadas, detalhando as possibilidades, as estratégias e os desafios da experiência do ensino das lutas nos anos finais do ensino fundamental nas aulas de Educação Física com base na teoria do ensino centrada no aprendiz.

Conferindo voz aos educadores, os relatos da prática proporcionam a reflexão das ações no campo docente (NOGUEIRA, FARIAS E MALDONADO, 2017). Assim, o relato de experiência compreende “(...) o currículo em ação narrado justamente por aqueles que planejam, desenvolvem e avaliam o processo" (NEIRA, 2017, p. 54), apresentando caminhos seguidos, as certezas, dúvidas, desejos, objetivos das práticas, as atividades realizadas, as respostas dos estudantes ao processo, os instrumentos avaliativos utilizados, os resultados obtidos e as percepções dos docentes que implementaram a prática (NEIRA, 2017).

Para a elaboração do relato, utilizaram-se experiências vivenciadas, planejamento pedagógico da professora, registros feitos por ela, posteriores às práticas de lutas desenvolvidas com os estudantes. A fim de melhor compreender e analisar os resultados obtidos, a professora reuniu-se com outros docentes para refletir sobre as etapas realizadas e discuti-las, visando apresentar resultados e interpretações os mais fiéis possíveis. Ressalta-se que, nesse estudo, foi assegurado o anonimato dos estudantes e da escola em que foi realizada a experiência.

Saberes e práticas desenvolvidos e experienciados são aqui apresentados, na sequência pedagógica construída e executada, em três partes: a primeira relacionada ao desenvolvimento do conteúdo lutas nas aulas de Educação Física; a segunda referente ao desenvolvimento da 
avaliação prática de lutas; a terceira relativa ao Festival de Lutas realizado na escola com profissionais desta modalidade.

\subsection{DeSEnVOLVIMENTO das LUTAS NAS AUlas de EdUCAÇão FísiCa}

No início da trajetória, muitos estudantes relataram a experiência prévia em relação ao conteúdo 'lutas'. Foi preciso, no entanto, levá-los a reconhecê-lo como um conteúdo legítimo das aulas de Educação Física Escolar, por serem recorrentes, nas aulas iniciais, frases como: "Isso pode na escola?"; "Ah, eu vou me machucar! ", "Faz parte da Educação Física isso?”; "Eu nunca vi isso na escola". Em consequência, realizou-se um debate a respeito de conceitos, significados e diferenças de luta e de briga, visando esclarecer as desigualdades entre combate e violência consciente (SANTOS; BRASIL, 2018). Com esta finalidade, foram sistematizadas questões como "O que é luta?", "Qual a diferença entre luta e briga?", "Qual o objetivo de se ensinar/aprender a luta na escola?",

As questões foram tratadas e dialogadas em pequenos e grandes grupos de estudantes, em uma aula teórica introdutória. Os questionamentos geraram debates, os quais se respaldaram em livros, reportagens, sites das federações, fotos, vídeos que ilustraram as falas dos grupos.

Houve, por conseguinte, a compreensão de que a luta também pode ser vista como esporte, pois é regida por regras, por condutas éticas, por princípios resguardados pelas federações, estando o respeito pelo adversário sempre presente. A professora propôs então uma aula, na qual estudantes, que já tinham contato com diferentes tipos de lutas, foram convidados a demonstrar seus saberes aos colegas, com o objetivo de valorizar o processo, os conhecimentos e as experiências individuais. Do ponto de vista construtivista, oferecer tempo e espaço para que os estudantes atribuam seus próprios significados aos conteúdos valoriza a cultura que eles trazem em sua bagagem. É oportuno, portanto, possibilitar reflexões críticas sobre a prática das lutas e incentivar a apresentação de sugestões e de mudanças no processo educativo (OLIVEIRA, 1997).

Aproximando, cada vez mais, os alunos do processo de ensino e de aprendizagem, em uma decisão compartilhada entre estudantes e professora, foram definidas as lutas que seriam abordadas nas aulas de Educação Física, sendo escolhidas: sumô, kung fu, esgrima, boxe, judô, aikido, capoeira, taekwondo. Em cada modalidade de luta, adotaram-se estratégias diversificadas e valorizaram-se os conhecimentos prévios dos estudantes. Definiu-se uma modalidade para cada aula, cujo planejamento incluía objetivos específicos, estratégias de ensino e aproveitamento das aulas. Ao final de cada aula, era feita uma reflexão crítica sobre o 
processo, por meio de diálogo e de feedback. Este tipo de iniciativa é incentivada nos estudos de Furtado, Monteiro e Vaz (2019), e Cruz et al., (2018), os quais reforçam a importância do debate.

O Quadro 1 apresenta a descrição dos tipos de lutas abordadas, os objetivos, as estratégias, o tempo de contato, o aproveitamento dos conteúdos.

Quadro 1 - Descrição das aulas dos diferentes tipos de luta

\begin{tabular}{|c|c|c|c|}
\hline Lutas & Objetivos & Estratégias & Aproveitamento \\
\hline Sumô & $\begin{array}{l}\text { Conhecer a história, a } \\
\text { indumentária, os } \\
\text { princípios, os golpes } \\
\text { e as regras que regem } \\
\text { esta luta }\end{array}$ & $\begin{array}{l}\text { Aula expositiva e aula } \\
\text { prática. Atividades em } \\
\text { duplas e grupos. } \\
\text { Contato: duas aulas. }\end{array}$ & $\begin{array}{l}\text { Grande aceitação. Percebeu-se que os } \\
\text { estudantes conseguiram dominar os } \\
\text { golpes e realizar, sem muita dificuldade, } \\
\text { as práticas propostas. }\end{array}$ \\
\hline Kung $F u$ & $\begin{array}{l}\text { Compreender os } \\
\text { valores, as } \\
\text { curiosidades, os } \\
\text { movimentos, os } \\
\text { diversos tipos de } \\
\text { armas e os principais } \\
\text { lutadores da história. }\end{array}$ & $\begin{array}{c}\text { Aula expositiva e aula } \\
\text { prática. Atividades em } \\
\text { duplas e em grupos. } \\
\text { Apresentação de trechos } \\
\text { dos filmes Kung } F u \text { Panda e } \\
\text { Karate Kid (2010). } \\
\text { Contato: duas aulas. }\end{array}$ & $\begin{array}{l}\text { Os alunos apresentaram um pouco de } \\
\text { dificuldade na realização das atividades, } \\
\text { em sua compreensão, na execução } \\
\text { controlada dos movimentos, no entanto } \\
\text { conseguiram ter grande aproveitamento. }\end{array}$ \\
\hline Esgrima & $\begin{array}{l}\text { Entender os objetivos } \\
\text { do combate e suas } \\
\text { regras, conhecer os } \\
\text { diferentes tipos de } \\
\text { armas, a } \\
\text { indumentária. } \\
\text { Executar a luta } \\
\text { propriamente dita. }\end{array}$ & $\begin{array}{l}\text { Aula prática de montagem } \\
\text { das espadas com jornal e } \\
\text { papel reciclado, exposição } \\
\text { geral do conteúdo, uma aula } \\
\text { de atividades em duplas. } \\
\text { Foram usados vídeos de } \\
\text { competições de esgrima das } \\
\text { Olimpíadas do Rio } 2016 . \\
\text { Contato: duas aulas. }\end{array}$ & $\begin{array}{l}\text { A aula de montagem das espadas foi } \\
\text { extremamente lúdica e bem aproveitada. } \\
\text { Na aula prática, todos os estudantes } \\
\text { conseguiram realizar os gestos } \\
\text { propostos, conciliando a atividade com } \\
\text { diversão. Houve aproveitamento geral. }\end{array}$ \\
\hline Boxe & $\begin{array}{l}\text { Proporcionar o } \\
\text { contato com o boxe, } \\
\text { compreender seu } \\
\text { contexto histórico, } \\
\text { suas características e } \\
\text { curiosidades, seus } \\
\text { principais golpes. }\end{array}$ & $\begin{array}{l}\text { Aula teórico-expositiva, } \\
\text { seguida de circuito com as } \\
\text { estações: força; velocidade; } \\
\text { agilidade; golpes } \\
\text { específicos. Utilizaram-se } \\
\text { músicas nas práticas para } \\
\text { aumentar o estímulo. } \\
\text { Contato: uma aula. }\end{array}$ & $\begin{array}{l}\text { Observaram-se grande entusiasmo e } \\
\text { muita expectativa por parte dos } \\
\text { estudantes, que se envolveram } \\
\text { fortemente nas atividades práticas. A } \\
\text { estratégia do estímulo musical tornou a } \\
\text { prática mais dinâmica, divertida e } \\
\text { prazerosa. }\end{array}$ \\
\hline Judô & $\begin{array}{l}\text { Compreender a } \\
\text { história, os princípios } \\
\text { filosóficos, as } \\
\text { curiosidades, a } \\
\text { indumentária e } \\
\text { alguns golpes. }\end{array}$ & $\begin{array}{l}\text { Aula prática e expositiva } \\
\text { dialogada (participação de } \\
\text { professor externo). } \\
\text { Contato: uma aula. }\end{array}$ & $\begin{array}{l}\text { Com a presença de um expert, os } \\
\text { estudantes demonstraram muito } \\
\text { interesse em conhecer e praticar a } \\
\text { modalidade. A interação entre os } \\
\text { estudantes e o professor convidado fez } \\
\text { com que os momentos dialogados se } \\
\text { tornassem ainda mais prazerosos que os } \\
\text { momentos de prática. }\end{array}$ \\
\hline Aikido & $\begin{array}{l}\text { Conhecer sua } \\
\text { história, suas armas, } \\
\text { os principais } \\
\text { lutadores, regras, } \\
\text { princípios e gestos da } \\
\text { luta. }\end{array}$ & $\begin{array}{l}\text { Aula expositiva dialogada e } \\
\text { apresentação de vídeos. } \\
\text { Aula prática com atividades } \\
\text { individuais, em duplas e em } \\
\text { grupos. } \\
\text { Contato: duas aulas. }\end{array}$ & $\begin{array}{l}\text { Muitos estudantes relataram não } \\
\text { conhecer a luta, o que tornou tudo uma } \\
\text { novidade. Na aula expositiva, ao } \\
\text { assistirem vídeos, muitos ficaram } \\
\text { desapontados, acharam a luta "sem } \\
\text { graça", "parada demais", porém, na aula } \\
\text { prática, isso se modificou. Com a } \\
\text { utilização de bastões (armas utilizadas }\end{array}$ \\
\hline
\end{tabular}




\begin{tabular}{|c|c|c|c|}
\hline & & & $\begin{array}{l}\text { no aikido), os estudantes mudaram sua } \\
\text { percepção e se divertiram. }\end{array}$ \\
\hline Capoeira* & $\begin{array}{l}\text { Assimilar o contexto } \\
\text { histórico-cultural; } \\
\text { conhecer sua origem } \\
\text { e seus movimentos. }\end{array}$ & $\begin{array}{l}\text { Aula expositiva e prática, } \\
\text { atividades em duplas e } \\
\text { grupos. } \\
\text { Contato: uma aula. }\end{array}$ & $\begin{array}{l}\text { A experiência prévia da maioria dos } \\
\text { estudantes facilitou o desenvolvimento } \\
\text { da aula. Os que conheciam esta } \\
\text { prática.auxiliaram os colegas que ainda } \\
\text { não a tinham vivenciado. Foi uma aula } \\
\text { colaborativa e coletivamente construída. }\end{array}$ \\
\hline Taekwondo & $\begin{array}{c}\text { Entender os } \\
\text { objetivos, as } \\
\text { pontuações, conhecer } \\
\text { a história, a } \\
\text { indumentária e } \\
\text { experenciar alguns } \\
\text { golpes. }\end{array}$ & $\begin{array}{c}\text { Aula expositiva ilustrada } \\
\text { com vídeos. Aula prática } \\
\text { com atividades em duplas e } \\
\text { em grupos. } \\
\text { Contato: duas aulas. }\end{array}$ & $\begin{array}{l}\text { A semelhança dos golpes com as lutas } \\
\text { anteriores facilitou o processo de } \\
\text { aprendizagem. Notou-se, grande } \\
\text { aproveitamento e envolvimento. }\end{array}$ \\
\hline
\end{tabular}

*A capoeira é compreendida como pluralidade: jogo, luta, dança e esporte (CAPOEIRA, 2001; BRASIL, 1998).

Fonte: Elaborado pelos autores, 2019.

Com base nos princípios do modelo de ensino centrado no aprendiz (WEIMER, 2002), a professora desempenhou o papel de facilitadora nos processos de ensino e de aprendizagem dos estilos, em seu desenvolvimento e na aquisição de informações. Pereira et al. (2017) realizaram uma pesquisa com o objetivo de apresentar, por meio de uma rede de jogos de lutas, uma sistematização do conteúdo de lutas para o ambiente escolar. Tal estudo reforçou a importância de o professor tornar-se um mediador nas aulas, propondo situações-problema, oportunizando a ampliação das competências interpretativas, incentivando a autonomia, permitindo a expressão da criatividade.

As lutas contempladas na presente investigação foram desenvolvidas com apoio em: práticas lúdicas; jogos; trechos de filmes, como no estudo de Chaves, Silva e Medeiros (2015); vídeos como suporte e introdução ao tema, como nos estudos de Ferreira (2006) e Lopez, Golin e Ribeiro (2019); e alguns movimentos básicos. Antes de os estudantes vivenciarem as lutas na prática, foram abordados, em aulas teóricas, os contextos históricos e culturais, as regras, os princípios morais e filosóficos, as curiosidades e as indumentárias específicas.

De acordo com Scapin et al. (2020), as aulas tornam-se mais significativas quando os alunos produzem o material didático que será adotado na aprendizagem, tornando-os assim sujeitos do processo educativo. O trabalho em grupo e o diálogo são salientados por Santos (2011). Os autores Santos e Brasil (2018) viram reforçados os benefícios dessa prática ao trabalharem com o ensino das lutas no ensino médio de uma escola pública de Niterói-RJ. Ressalta-se que nas aulas de esgrima e de boxe foi oportunizada aos estudantes a elaboração dos equipamentos com uso de materiais reciclados. A espada para a esgrima foi produzida com jornal e fita adesiva e as luvas para o boxe, confeccionadas com tiras de material TNT. Para a 
aula de aikido, utilizaram-se bastões feitos de cabos de vassoura trazidos de casa pelos estudantes.

Outra estratégia indicada, na literatura, como eficiente é a utilização de músicas como uma ferramenta de estímulo auditivo (DUTRA et al., 2016; SILVA; QUADROS, 2019), o que pode tornar a prática mais prazerosa (CORREIA; SPESSATTO, 2019). Em algumas aulas, utilizaram-se músicas, objetivando torná-las mais atrativas e divertidas. As músicas utilizadas foram: Rocky Balboa Remix e Survivor, Eye Of The Tiger Hyperbits Bender Remix, Eye Of The Tiger Lyrics (aula de boxe); Kung Fu Music Training, Wong Fei Hung (aula de kung fu); Aikido in music (aula de aikido); Tae Kwon Do (superación) Denys El Patriarca lyric (aula de taekwondo) e Capoeira Toque Berimbau (aula de capoeira).

Durante as aulas, visou-se desenvolver a autonomia progressiva dos estudantes oportunizando-lhes expor e compartilhar ideias, bem como auxiliar os colegas menos experientes (FOSNOT, 2005). Foram fornecidos feedbacks sobre a proposta de ensino de estilos de lutas, tornando os alunos protagonistas neste contexto.

$\mathrm{O}$ retorno dado pelos estudantes auxiliou e influenciou positivamente a estrutura das aulas, contribuindo para o desenvolvimento de um processo de ensino-aprendizagem flexível e centrado no aluno. Salienta-se a importância do envolvimento dos discentes no processo de ensino sob a perspectiva construtivista, que lhes possibilitou vivenciarem um contexto de reflexão, discussão e compartilhamento de ideias.

\subsection{DESENVOLVIMENTO da AVALIAÇão PRÁTICA DE LUTAS}

No contexto da experiência das lutas, após os estudantes vivenciarem as práticas propostas, foi feita uma avaliação levando-se em consideração os princípios do modelo de ensino centrado no aprendiz (WEIMER, 2002). Ela serviu não apenas para gerar notas, mas também para promover o aprendizado, o desenvolvimento da autonomia e a responsabilidade. A turma foi dividida em grupos definidos pela professora. Cada um sorteou uma luta para sobre ela planejar, produzir, ensaiar e preparar uma simulação de combate, a fim de mostrar, em uma dramatização cênica, os gestos básicos e as armas correspondentes (se fosse o caso). A apresentação deveria durar no mínimo três minutos e no máximo cinco minutos.

$\mathrm{Na}$ definição dos grupos, mesclaram-se estudantes com mais experiência em lutas com aqueles que ainda não apresentavam experiência, por este motivo os grupos foram elencados antecipadamente. Fato este que reforçou as características de um ambiente construtivista, com estímulo a um ambiente organizado, no qual os estudantes respeitam a participação de seus 
colegas e assumam papel ativo no processo (BIDARRA; FESTAS, 2005). Através de trabalhos em grupos, cultivou-se, portanto, um ambiente de desenvolvimento da autonomia e de interação social (SANCHIS; MAHFOUD, 2010).

Diante da proposta, muitos estudantes mostraram-se confiantes e motivados em realizar a atividade. Para a elaboração e o ensaio das apresentações, foram destinadas quatro aulas. As estratégias de avaliação encontram-se explanadas no Quadro 2, com os respectivos critérios, o tempo disposto para o desenvolvimento e as notas estipuladas.

Quadro 2 - Processo de avaliação da aprendizagem das lutas

\begin{tabular}{|c|c|c|c|}
\hline Avaliações & Critérios de avaliação & Tempo & Notas \\
\hline $\begin{array}{c}\text { Desenvolvimento e } \\
\text { preparação para a } \\
\text { apresentação }\end{array}$ & $\begin{array}{c}\text { Comprometimento com os pares, elaboração da } \\
\text { encenação de combate, dedicação, } \\
\text { responsabilidade com o grupo e com o objetivo } \\
\text { proposto. }\end{array}$ & $\begin{array}{c}\text { Quatro aulas de } \\
45 \text { minutos cada }\end{array}$ & 0 a 10 \\
\hline $\begin{array}{c}\text { Apresentação final da } \\
\text { luta }\end{array}$ & $\begin{array}{c}\text { Criatividade na encenação do combate, } \\
\text { indumentária de acordo com a luta representada, } \\
\text { domínio sobre o conteúdo. }\end{array}$ & $\begin{array}{c}\text { Apresentação } \\
\text { final - mínimo } \\
\text { três minutos e } \\
\text { máximo de cinco } \\
\text { minutos. }\end{array}$ & 0 a 10 \\
\hline
\end{tabular}

Fonte: Elaborado pelos autores, 2019.

Concluídos o desenvolvimento e a produção da apresentação, os estudantes demonstraram aos colegas de classe o que produziram. As apresentações foram realizadas na quadra de esportes da escola. Ao final de cada uma, a professora (sem mencionar notas) e os colegas de classe realizavam um feedback ao grupo que havia se apresentado. Nestes momentos, os estudantes compartilharam as facilidades e os desafios da produção realizada, e os colegas de classe (espectadores) puderam expor suas dúvidas em relação à luta encenada e explanar suas ideias. Momentos semelhantes são observados no estudo de Kawashima; Silva e Moreira (2020), porém relativos ao conteúdo de ginástica laboral. Neste estudo, os alunos tinham que construir, em grupo, um programa de ginástica laboral e apresentá-lo para a turma, ao final, podiam expor sugestões e ideias, contribuindo com as discussões e as reflexões sobre o tema.

\subsection{COMPARTILHANDO EXPERIÊNCIAS: O FESTIVAL DE LUTAS}

O objetivo da realização do Festival foi, além de ampliar o contato dos estudantes para com as diferentes modalidades de lutas, aproximar a realidade dos profissionais (professores, mestres, senseis) com o ambiente escolar. Por conseguinte, sugeriu-se à direção da escola convidar profissionais experientes para compartilharem seus saberes e vivências com os estudantes, instigando a conexão entre a escola e a comunidade. Possibilitar esse diálogo entre 
estudantes e profissionais da área reforçaria os conteúdos e aproximaria os estudantes da realidade de combate, divulgando seus fundamentos e princípios, possibilitando a reflexão e incentivando a continuidade da prática extraclasse.

Os autores Maldonado e Bocchini (2013), ao abordarem este mesmo conteúdo com o $5^{\circ}$ ano, sugerem caminhadas pelo bairro com os estudantes para visitar escolas de lutas, visando uma prática enriquecedora que ultrapasse os muros da escola. Outras alternativas de atividades que podem ser contempladas nesta abordagem são: pesquisas, debates, palestras, visitações, análises de vídeos, de filmes ou de fotos, encenações, produção textual ou audiovisual (NASCIMENTO, 2008). Nas discussões, pode ser tratado sobre as experiências de vida, traçando paralelos com o próprio cotidiano, e sobre assuntos como respeito e filosofia das lutas, concentração, respiração e atitudes com os oponentes (CARREIRO, 2005).

Após a permissão concedida pela gestão escolar, a professora, através de redes sociais e de aplicativos de comunicação. contatou, por meio de dispositivo móvel, 12 profissionais, contudo apenas seis aceitaram participar do evento, sendo aberta a possibilidade de divulgação de suas especialidades, bem como das respectivas academias. Destaca-se, inicialmente, que foram procuradas as academias de lutas inseridas na comunidade em torno da escola, o que provavelmente facilitou o aceite dos profissionais.

O Festival de Lutas ocorreu no período matutino, no horário das 10 horas até às $11 \mathrm{~h} 30 \mathrm{~min}$ e no vespertino, das $15 \mathrm{~h} 30 \mathrm{~min}$ até às $17 \mathrm{~h}$. No período matutino, estiveram presentes professores de judô, taekwondo, kung fu e karatê. No período vespertino, contou-se com a presença destes mesmos profissionais e também de profissionais de aikido. Nos dois períodos, houve momentos de integração com os estudantes, quando eles foram convidados a entrar no tatame para participar das lutas.

O Festival foi realizado na quadra da escola, na qual foi demarcada uma área para a realização das apresentações. Foram utilizados tatames emprestados por uma academia de luta próxima da escola, sendo colocados cones à sua volta, com espaço de três metros entre eles e fitas de elástico de um cone ao outro, delimitando melhor o espaço e a área de segurança.

Visando a uma proposta multidisciplinar, foram envolvidos outros professores e setores da escola na realização do Festival. Contou-se com a colaboração do professor da banda musical da escola para auxiliar o manuseio dos equipamentos de som e dos microfones. Os outros professores de Educação Física colaboraram com a arrumação do espaço, as coordenadoras auxiliaram na organização dos estudantes na quadra esportiva e a professora de Educação Física responsável pelas turmas assumiu a logística e o cerimonial do Festival. O trabalho coletivo e 
o comprometimento de todos os envolvidos contribuiu para a aproximação da teoria com a prática, bem como para a realização de algo novo na escola, corroborando o estudo de Trevisan; Trevisan e Ribeiro (2018), o qual evidencia que a estreita relação entre teoria e prática e o trabalho em conjunto dos professores colaboram para práticas e projetos bem sucedidos no contexto escolar.

$\mathrm{Na}$ abertura do Festival, todos os profissionais convidados foram apresentados. Após, em ordem preestabelecida, cada profissional e sua equipe (caso estivesse acompanhado por estudantes e/ou auxiliares) tinham até vinte minutos para demonstrar seus saberes. Alguns estudantes que faziam parte dessas academias, também participaram do evento.

Em todas as apresentações foram colocadas como músicas de fundo, as mesmas utilizadas no desenvolvimento do processo de ensino e aprendizagem em lutas, conforme anteriormente combinado com os profissionais.

\section{Resultados}

Um planejamento diversificado, visando ampliar os conhecimentos e o repertório motor dos estudantes por meio de novas experiências, constituiu o objetivo geral das aulas de Educação Física relatadas neste estudo. Comumente, percebem-se aulas em que a frequência e intensidade dos conteúdos abordados não se equivalem, refletindo a realidade limitada à prática de esportes, a qual reflete a falta de opções. A expectativa que se tem para as aulas de Educação Física Escolar é que o mesmo espaço-tempo que viabiliza o futebol viabilize igualmente o tênis, a dança, a ginástica, as atividades aeróbicas, o relaxamento, o atletismo, entre outras modalidades esportivas (DAOLIO, 1996; BRASIL, 1998; FENSTERSEIFER; SILVA, 2011; MERIDA; MERIDA, 2013). A Figura 1 exemplifica o cenário real da Educação Física Escolar brasileira e o que é esperado, no âmbito escolar, em relação à prática e à frequência dos conteúdos. 
Figura 1 - Divisão dos conteúdos abordados na Educação Física Escolar: realidade x expectativa

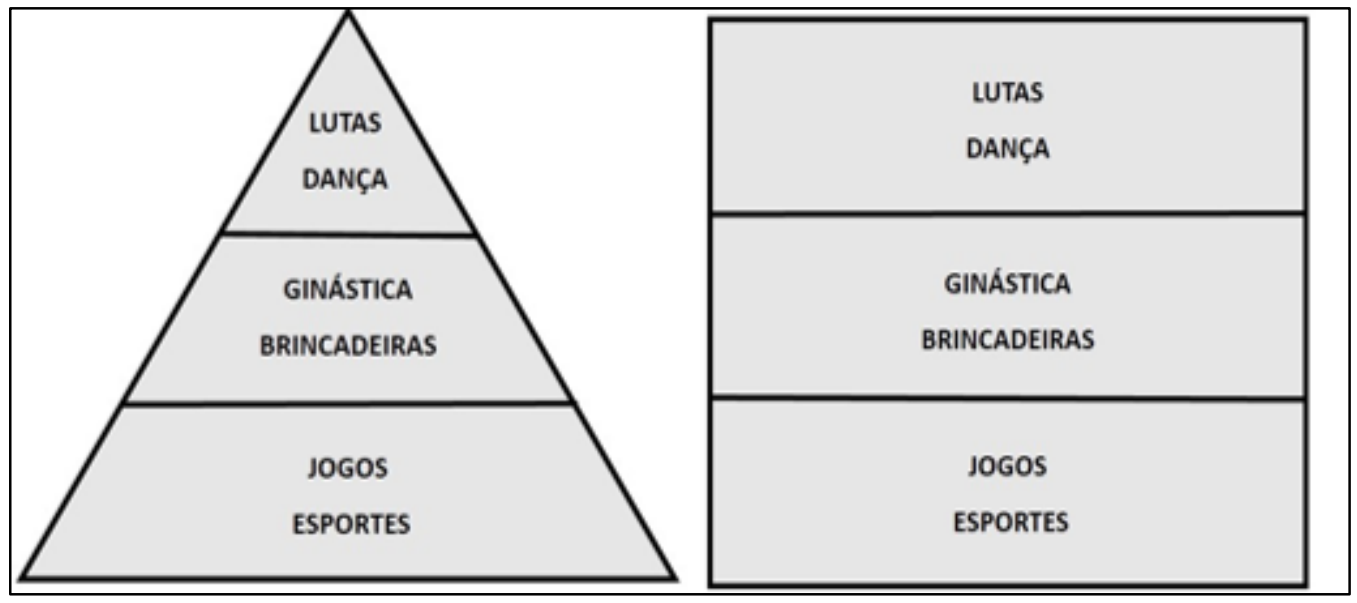

Fonte: Elaborada pelos autores, 2019.

Considerando o cenário da Educação Física no contexto escolar, objetivou-se propor, através deste estudo, um planejamento anual que contemple, de forma igualitária, as diversas manifestações da cultura corporal de movimento, até então não implementadas na escola. As atividades realizadas culminaram com o reconhecimento e a valorização do componente curricular por toda a comunidade escolar, principalmente, pelos estudantes e seus pais. Ponderase, portanto, que a Educação Física Escolar, contemplando e oportunizando aos estudantes diversos conteúdos e abandonando a monocultura esportiva, impulsionará um processo enriquecedor e de real valorização da área.

Em relação ao processo de desenvolvimento do ensino e aprendizagem, visou-se dispor, em seu centro, os estudantes, oferecendo a eles possibilidades de desempenharem papéis ativos nas tomadas de decisão. Nas quatro aulas cedidas para a produção das apresentações, verificouse que, em muitos grupos, despertaram a liderança e a solidariedade. No dia das apresentações, observou-se que, os estudantes conseguiram desempenhar com criatividade o que foi solicitado. Obviamente, eles não se tornaram atletas de artes marciais, porém não era essa a finalidade proposta e sim ampliar seu contato com as várias modalidades e possibilitar-lhes vivências diversificadas. Pelos resultados positivos das apresentações, considera-se que o objetivo almejado foi alcançado.

A experiência com profissionais da área de lutas foi algo inesperado para os estudantes, tendo resultado em retornos favoráveis. Pode-se citar, como exemplo, seis estudantes que passaram a participar de academias de lutas na região escolar. Outro ponto de destaque foram as interações com os profissionais, após as apresentações. O diálogo reforçou aos estudantes que é possível praticar outras modalidades da Educação Física e obter muitos benefícios físicos, mentais, sociais e espirituais. 
No desenvolvimento de processos de ensino e de aprendizagem de um conteúdo ao qual o contexto escolar não está habituado em suas aulas, revelam-se desafios que instigam a procura de soluções para o alcance dos melhores resultados. Alguns dos desafios encontrados durante as práticas das aulas foram: falta de condicionamento físico nas aulas de circuito do boxe; a falta de coordenação motora na realização dos golpes, também relatada no estudo de Chaves, Silva e Medeiros (2015) e falta de decisão rápida na realização dos golpes de kung fu. A estrutura e os materiais não constituíram dificuldades, pois a escola tem excelente estrutura e os materiais, quando insuficientes ou ausentes, foram adaptados ou produzidos (espada, luvas, bastões) com diferentes elementos (TNT, jornal, cabo de vassoura, cano), em concordância com o que preconiza o estudo de Santos e Brasil (2018). Ressalta-se que confeccionar os materiais é uma maneira de instigar o engajamento dos estudantes, como mostra o estudo de Silva (2017), em que, nas aulas de Física, foram utilizados materiais de baixo custo para experimentações e construções. Esta é igualmente uma forma de tornar a aula mais significativa, como evidenciam os relatos do estudo de Almeida e Martins (2020), no qual os estudantes construíram embarcações alternativas com materiais reutilizáveis. Os autores Santos e Brandão (2019), ao destacarem a análise do panorama de pesquisas realizadas em lutas, relataram que a infraestrutura e a ausência de materiais são referidas como causas prejudiciais para o ensino deste conteúdo nas aulas de Educação Física.

Quanto à participação e à disciplina dos estudantes, reforça-se que a experiência de usufruir 'o novo' já havia ocorrido nas aulas, ou seja, as expectativas dos estudantes e da professora eram as melhores desde o princípio. Maldonado e Bocchini (2013) expõem sobre a indisciplina dos estudantes e ressaltam: "Não podemos afirmar que esse projeto diminuiu a violência e o desrespeito existente entre os estudantes, [...], mas temos clareza de ter provocado reflexões iniciais nas crianças no sentido de diminuir toda a agressividade e a violência entre eles na vida escolar cotidiana” (p. 209). Lopes, Golin e Ribeiro (2019) descrevem, nos resultados de seu estudo, que "as práticas de Lutas na verdade podem minimizar e/ou evitar episódios agressivos, especialmente ao valorizar a disciplina, a ética, o respeito e o autocontrole, influenciando o desenvolvimento do caráter do sujeito praticante" (p. 9).

A falta de domínio do conteúdo prático de lutas pela professora formou um dos desafios no ensino do tema, semelhante ao observado no estudo de Rufino e Darido (2015). Destaca-se, porém, que, para implementar tal conteúdo, não é necessário ser expert na modalidade e muito menos tê-la praticado como atleta (GALATTI; CIRINO; SCAGLIA, 2015). 
Com a implementação das lutas no contexto escolar, adotando o modelo de ensino centrado no aprendiz, estabeleceu-se um ambiente de diálogo e reflexão, que partiu dos conhecimentos prévios dos estudantes. No decorrer do processo, eles compartilharam ideias; tomaram decisões; assumiram papéis ativos; desenvolveram habilidades como a criatividade, a empatia e a reflexividade; ampliaram a consciência de si e reconheceram a necessidade de assumir maior responsabilidade pelo próprio aprendizado.

Os resultados obtidos ultrapassaram aqueles esperados, pois a implementação das lutas nas aulas de Educação Física impactou não só os estudantes, mas também a professora e a comunidade escolar (professores, gestão escolar). Embora existam dificuldades e desafios durante a trajetória, o importante é valorizar as soluções, a aprendizagem significativa, o processo e os valores alcançados e desenvolvidos com e pelos estudantes.

\section{CONSIDERAÇões FinaIS}

A Educação Física Escolar abrange as manifestações da cultura corporal de movimento. No entanto, algumas temáticas, como as práticas corporais de lutas, não são proporcionadas aos educandos com as mesmas frequência e intensidade quando comparadas a outros conteúdos. Provavelmente, isto se deve à falta de domínio e de afinidade dos professores com tais saberes, o que, porém, não deve se transformar em empecilho para a implementação destas temáticas no contexto escolar.

A inserção das lutas no âmbito escolar foi fundamentada na teoria do ensino centrada no aprendiz, visando promover a autonomia, a responsabilidade e o papel ativo dos estudantes durante o processo de ensino e aprendizagem, desempenhando o professor, neste contexto, o papel de facilitador e não de protagonista. As estratégias planejadas foram: aulas expositivas com auxílio de vídeos, aulas dialogadas e aulas práticas. Como avaliação, propôs-se uma apresentação em grupo, na qual os educandos deveriam encenar um combate, possibilitandolhes, desta forma, um papel ativo. Intentou-se ampliar as experiências dos educandos pelo compartilhamento de saberes com profissionais da área. Desafios como a necessidade de preparo de capacidades físicas e motoras específicas, bem como o desenvolvimento da tomada de decisão rápida, e ressignificação de conceitos de luta e de briga também fizeram parte de todo o processo.

Pela realização deste estudo, compreende-se que o mais significativo foi oportunizar a experiência das lutas, raramente implementada nas aulas de Educação Física, de maneira que os estudantes fossem os protagonistas do processo de ensino e aprendizagem. Os alunos 
assumiram papéis ativos, tornando as aulas mais significativas e prazerosas. Outro ponto relevante foi a valorização dos profissionais de lutas, possibilitando o diálogo entre escola e comunidade, através da conexão, da valorização e do compartilhamento de experiências.

Destacamos a importância dessa pesquisa e os resultados obtidos no campo do ensino da Educação Física e do ensino centrado no aprendiz, haja vista a necessidade de ampliar reflexões acerca das possibilidades, estratégias e desafios relacionados a práticas pedagógicas de professores e processo de ensino e aprendizagem que envolvam os diferentes conteúdos no campo do ensino. Todavia, esse estudo não esgota a temática, apontando para outros caminhos que deem continuidade a esta investigação, como futuros estudos que relatem a inovação e intervenção dos diferentes conteúdos na Educação Física Escolar, a implementação de espaços de aprendizagem diversificados como os festivais, e o uso de tecnologias da informação como ferramentas de ensino, como filmes, músicas, entre outros, como estratégia de universalização de conteúdos educacionais.

Assim, pretende-se possibilitar que os alunos se sintam valorizados e motivados com as práticas pedagógicas, com as metodologias e avaliações adotadas, tornando-os protagonistas do seu processo, contribuindo para a formação de indivíduos críticos e autônomos, capazes de agir no e sobre o mundo.

\section{REFERÊNCIAS}

ALMEIDA, Luciano de; MARTINS, Fabrício Döring. Educação Física Escolar no ensino médio integrado: limites e possibilidades de uma proposta de intervenção. Revista Prática Docente, Confresa, v. 5, n. 1, p. 100-120, jan/abr 2020. Disponível em: https://doi.org/10.23926/RPD.2526-2149.2020.v5.n1.p100-120.id635. Acessado em: 10 jun. 2020.

BIDARRA; Maria da Graça Amaro; FESTAS, Maria Isabel Ferraz. Construtivismo(s): Implicações e Interpretações Educativas. Revista Portuguesa de Pedagogia, Coimbra, v. 39, n. 2, p. 177-195, 2005. Disponível em: https://eg.uc.pt/handle/10316/11548. Acessado em: 10 mar. 2020.

BRASIL. Secretaria de Educação Fundamental. Parâmetros Curriculares Nacionais: Educação Física, 3o e 4o ciclos. Brasília: MEC / SEF, 1998.

BRASIL. Secretaria de Educação Fundamental. Parâmetros Curriculares Nacionais: Educação Física, ensino de quinta a oitava séries. Brasília: MEC / SEF, 1998.

BRASIL. Ministério da educação. Base Nacional Comum Curricular: Educação é a base. Brasília: MEC, 2017.

BRASIL. Ministério da Educação e do Desporto. Lei de Diretrizes e Bases da Educação Nacional, Lei no 9.394 de 20 de dezembro de 1996. 
CAPOEIRA, Nestor. Capoeira: os fundamentos da malícia. Rio de Janeiro: Record, 2001.

CARREIRO, Eduardo Augusto. Lutas. In: DARIDO, Suraya Cristina. Educação Física

Escolar: implicações para a prática pedagógica. Rio de Janeiro: Guanabara Koogan, 2005.

CHAVES, Paula Nunes; SILVA, Ivana Lúcia da; MEDEIROS, Rosie Marie Nascimento de. Lutas na Educação Física Escolar: uma experiência no ensino médio. Cadernos de

Formação RBCE, v. 5, n. 2, p. 80-91, 2015. Disponível em:

http://revista.cbce.org.br/index.php/cadernos/article/view/2011/1023. Acessado em: 15 mar. 2020.

CIRINO, Cirino; PEREIRA, Marcos Paulo Vaz de Campos; SCAGLIA, Alcides José Sistematização dos Conteúdos das Lutas para o Ensino Fundamental: uma proposta de ensino pautada nos jogos. Revista Mineira de Educação Física, Viçosa, v. especial, n. 9, p. 221$227,2013$.

CORREIA, Carolini de Souza Vilela; SPESSATTO, Marizete Bortolanza. No ritmo da música: análise de uma experiência com estudantes do ensino médio em aulas de Sociologia. Revista Prática Docente, Confresa, v. 4, n. 2, p. 852-868, jul/dez 2019. Disponível em: https://doi.org/10.23926/RPD.2526-2149.2019.v4.n2.p852-868.id543. Acessado em: 10 jun. 2020.

CRUZ, Marlon Messias Santana; CASTRO NETA, Abília Ana; SORTE, Drieli Fernandes Boa; SANTOS, Joice Tainá de Jesus; MEDEIROS, Ana Gabriela Alves. Tematizando as lutas na Educação Física Escolar: relato de uma prática pedagógica no contexto do PIBID.

Caderno de Educação Física e Esporte, v. 16, n. 1, p. 109-115, 2018. Disponível em: http://e-revista.unioeste.br/index.php/cadernoedfisica/article/view/18778. Acessado em: 05 mar. 2020.

DAOLIO, Jocimar. Educação Física Escolar: em busca da pluralidade. Revista Paulista de Educação Física, São Paulo, supl. 2, p. 40-42, 1996. Disponível em: http://www.revistas.usp.br/rpef/article/view/139646. Acessado em: 31 jul. 2017.

DARIDO, Suraya Cristina; GALVÃO, Zenaide; FERREIRA, Lilian Aparecida; FIORIN, Giovanna. Educação Física no Ensino Médio: Reflexões e ações. Motriz, Rio Claro, v. 5, n. 2, p. 138-145, 1999.

DENZIN, Norman Kent; LINCOLN, Yvonna Sessions. O planejamento da pesquisa qualitativa: teorias e abordagens. In: $O$ planejamento da pesquisa qualitativa: teorias e abordagens. 2006. p. 432-432.

SANTOS, Rosane Barreto dos; BRASIL, Isabella Blanche Gonçalves. Vivenciando o conteúdo lutas na educação física escolar. Temas em Educação Física Escolar, v. 3, n. 1, p. 60-65, 2018. Disponível em:

https://www.cp2.g12.br/ojs/index.php/temasemedfisicaescolar/article/view/2093. Acessado em: 08 fev. 2020.

DUTRA, Higor; TAVARES, Andressa Silva; SANTOS, Emerson Luiz; COPETTI, Jaqueline. A importância da música na Educação Física: relato de experiência do estágio supervisionado 1. In: Salão internacional de ensino, pesquisa e extensão, 2016, Uruguaiana. Anais... 
Uruguaiana: UNIPAMPA, 2016. v. 8, n. 1, p. 1-8. Disponível em https://periodicos.unipampa.edu.br/index.php/SIEPE/article/view/84718. Acessado em: 10 mar. 2020.

FENSTERSEIFER, Paulo Evaldo; SILVA, Marlon André. Ensaiando o "novo" em Educação Física Escolar: a perspectiva de seus atores. Revista brasileira de ciências do esporte, Porto Alegre, v. 33, n. 1, p. 119-134, 2011. Disponível em: http://revista.cbce.org.br/index.php/RBCE/article/view/874. Acessado em: 18 jan. 2020.

FERREIRA, Heraldo Simões. As Lutas na Educação Física Escolar. Revista de Educação Física. Fortaleza, n.135, p.36-44, 2006.

FOSNOT, Catherine Twomey. Constructivism: Theory, perspectives and practice. New York: Teachers College, 2005.

FURTADO, Renan Santos; PINHEIRO, Elaine Cristina Monteiro; VAZ, Alexandre Fernandez. Lutas no ensino médio: conhecimento e ensino. Cadernos de Formação RBCE, Rio de Janeiro, v. 10, n. 1, p. 57-69, 2019. Disponível em http://revista.cbce.org.br/index.php/cadernos/article/view/2359. Acessado em: 10 mar. 2020.

GALATTI, Larissa Rafaela; CIRINO, Carolina; SCAGLIA, Alcides José. Reflexões metodológicas do ensino para o processo de iniciação esportiva das lutas. In: NASCIMENTO, Juarez Vieira; SOUZA, Edison Roberto; RAMOS, Valmor; ROCHA, Julio Cesar Schmitt. C. S. (Orgs.). Educação Física e Esporte: convergindo para novos caminhos... Florianópolis: UDESC, 2015. p. 489-511.

GOMES, Mariana Simões Pimentel. Procedimentos pedagógicos para o ensino das lutas: contextos e possibilidades. 2008. 139 f. Campinas: Dissertação (Mestrado em Educação Física) - Universidade Estadual de Campinas, Campinas, 2008.

KAWASHIMA, Larissa Beraldo; SILVA, Ana Paula Vasconcelos da; MOREIRA, Evando Carlos. Experiências com o ensino médio integrado do IFMT: a ginástica laboral como conteúdo da Educação Física. Revista Prática Docente, Confresa, v. 5, n. 1, p. 81-99, jan/abr 2020. Disponível em: https://doi.org/10.23926/RPD.2526-2149.2020.v5.n1.p81-99.id629. Acessado em: 10 jun. 2020.

LOPEZ, Paulo Cesar Grulett, GOLIN, Carlo Henrique, RIBEIRO, Edineia Aparecida Gomes. O conteúdo lutas no ensino médio: discursos dos professores de Educação Física da fronteira Brasil-Bolívia. Pensar a Prática, Goiânia, v.22, n. 1, p. 1-12, 2019. Disponível em: https://www.revistas.ufg.br/fef/article/view/54938. Acessado em: 10 jan. 2020.

MALDONADO, Daniel. Teixeira BOCCHINI, Daniel. As três dimensões do conteúdo na Educação Física: tematizando as lutas na escola pública. Conexões, Campinas, v. 11, n. 4, p. 195-211, 2013. Disponível em:

https://periodicos.sbu.unicamp.br/ojs/index.php/conexoes/article/view/8637599. Acessado em: 06 mar. 2020.

MERIDA, Fernanda Vieira; MERIDA, Marcos. Abordagem esportivista. In: SILVA, Sheila Aparecida Pereira dos Santos. Portas abertas para a Educação Física: falando sobre abordagens pedagógicas. São Paulo: Phorte, 2013. p. 37 - 49. 
MIRANDA, André Luis Ferreira; DOS REIS, Lion Matheus Cardoso. O conteúdo lutas nas aulas de Educação Física nas escolas de ensino fundamental do município de São Miguel do Guamá-PA. Instrumento: Revista de Estudo e Pesquisa em Educação, v. 22, n. 1, p. 120136, 2020. Disponível em: https://doi.org/10.34019/1984-5499.2020.v22.27888. Acessado em: 06 jun. 2020.

NASCIMENTO, Paulo Rogério Barbosa. Organização e Trato Pedagógico do Conteúdo de Lutas na Educação Física Escolar. Motrivivência, Florianópolis, v. 20, n. 31, p. 36-49, 2008. Disponível em: https://periodicos.ufsc.br/index.php/motrivivencia/article/view/21758042.2008n31p36. Acessado em: 23 jun. 2018.

NASCIMENTO, Paulo Rogério Barbosa do; ALMEIDA, Luciano. A tematização das lutas na Educação Física Escolar: restrições e possibilidades. Revista Movimento. Porto Alegre, v. 13, n.3, p. 91-110, 2007. Disponível em: https://seer.ufrgs.br/Movimento/article/view/3567. Acessado em: 10 dez. 2019.

NEIRA, Marcos Garcia. Análise e produção de relatos de experiência da educação física cultural: uma alternativa para a formação de professores. Textos FCC, v. 53, p. 53-103, 2017. Disponível em:

http://publicacoes.fcc.org.br/ojs/index.php/textosfcc/article/viewFile/5552/3586. Acessado em: 25 ago. 2020.

NOGUEIRA, Valdilene Aline; FARIAS, Uirá de Siqueira; MALDONADO, Daniel Teixeira. Práticas Pedagógicas inovadoras nas aulas de Educação Física Escolar: indícios de mudanças 2. Curitiba: CRV, 2017.

OLIVEIRA, Amauri Bássoli de. Metodologias emergentes no ensino da Educação Física. Revista da Educação Física, Maringá, v. 8, n.1, p. 21-27, 1997.

OLIVIER, Jean Claude. Das brigas aos jogos com regras: enfrentando a indisciplina na escola. Porto Alegre: Artmed, 2000.

PEREIRA, Marcos Paulo Vaz de Campos, CIRINO, Cirino, CORREAA, Adriano Oliveira, FARIAS, Gelcemar Oliveira. Lutas na escola: sistematização do conteúdo por meio a teia do conhecimento das lutas em rede. Conexões, Campinas v.15, n.3, p. 338-348, 2017.

Disponível em:

https://periodicos.sbu.unicamp.br/ojs/index.php/conexoes/article/view/8648512. Acessado em: 07 mar. 2019.

ROSÁRIO, Luís Fernando; DARIDO, Suraya Cristina. A Sistematização dos conteúdos da Educação Física na escola: a perspectiva dos professores experientes. Revista Motriz, Rio Claro, v. 11, n. 3. p. 167-178, 2005.

RUFINO, Luiz Gustavo Bonatto. DARIDO, Suraya Cristina. Possíveis diálogos entre a Educação Física Escolar e o conteúdo das lutas na perspectiva da cultura corporal. Conexões, Campinas, v. 11, n. 1, p. 145-170, 2013. Disponível em:

https://periodicos.sbu.unicamp.br/ojs/index.php/conexoes/article/view/8637635. Acessado em: 10 mar. 2020. 
RUFINO, Luiz Gustavo Bonatto; DARIDO, Suraya Cristina. O ensino das lutas na escola: possibilidades para a Educação Física. Porto Alegre: Penso Editora, 2015.

SANCHIS, Isabelle de Paiva; MAHFOUD, Miguel. Construtivismo: desdobramentos teóricos e no campo da educação. Revista Eletrônica de Educação, São Carlos, v. 4, n. 1, 2010.

Disponível em: http://www.reveduc.ufscar.br/index.php/reveduc/article/view/120. Acessado em: 10 mar. 2020.

SANTOS, Marcio Antonio Raiol; BRANDÃO, Pedro Paulo Souza. Produção do conhecimento em lutas no currículo da Educação Física Escolar. Movimento, Porto Alegre, v. 25, n. 24, p. 1-13, 2019. Disponível em:

https://seer.ufrgs.br/Movimento/article/view/78143/52719. Acessado em: 10 mar. 2020.

SANTOS, Sérgio Oliveira dos. Utilizando recursos materiais alternativos nas aulas de Educação Física Escolar. In: MOREIRA, Evandro Carlos; PEREIRA, Raquel Stoilov. Educação Física Escolar: desafios e propostas 2. Várzea Paulista: Fontoura: 2011.

SCAPIN, Gislei José; Camargo, Maria Cecília da Silva; Souza, Maristela da Silva; Costa, Leandra; Charão, Carine Marques. A construção de material pedagógico para o ensino do jogo e o processo educativo na Educação Física crítico-superadora. Motrivivência, Florianópolis, v. 32, n. 61, p. 01-20, abr. 2020. Disponível em: https://periodicos.ufsc.br/index.php/motrivivencia/article/view/2175-8042.2020e61616/0. Acessado em: 10 mar. 2020.

SILVA, Marcelo Luiz. O uso de materiais de baixo custo para experimentação nas aulas de densidade e pressão hidrostática. Revista Prática Docente, Confresa, v. 2, n. 1, p. 62-70, jan/jun 2017. Disponível em: https://doi.org/10.23926/rpd.v2i1.47. Acessado em: 10 jun. 2020 .

SILVA, Eurípedes Norberta da; QUADROS, Imara Pizzato. Educação musical na perspectiva metodológica de aprendizagem interdisciplinar. Revista Prática Docente, Confresa, v. 4, n. 1, p. 134-153, jan/jun 2019. Disponível em: https://doi.org/10.23926/RPD.25262149.2019.v4.n1.p134-153.id305. Acessado em: 10 jun. 2020.

TREVISAN; Andreia Cristina Rodrigues; TREVISAN, Eberson Paulo; RIBEIRO, Katia Dias Ferreira A relação entre teoria e prática no processo de desenvolvimento profissional docente: o caso da Escola Luiza Nunes Bezerra. Revista Prática Docente, Confresa, v. 3, n. 1, p. 352365, jan/jun 2018. Disponível em: https://doi.org/10.23926/RPD.2526-2149.2018.v3.n1.p352365.id176. Acessado em: 10 jun. 2020.

WEIMER, Maryellen. Learner-centered teaching: Five key changes to practice. New Jersey: John Wiley \& Sons, 2002.

WEIMER, Maryellen. Learner-centered teaching: Five key changes to practice. San Francisco: Jossey- bass, 2013.

Recebido em: 12 de junho de 2020.

Aprovado em: 28 de agosto de 2020. 